\title{
Exploring the Hidden Curriculum in Physical Education
}

\author{
Jinhong Jung1, James Ressler², Amy Linder ${ }^{1}$ \\ ${ }^{1}$ Department of Physical Education and Recreation, North Carolina Central University, Durham, USA \\ ${ }^{2}$ Department of Kinesiology, Northern Illinois University, DeKalb, USA \\ Email:jjung@nccu.edu
}

How to cite this paper: Jung, J., Ressler, J., \& Linder, A. (2018). Exploring the Hidden Curriculum in Physical Education. Advances in Physical Education, 8, 253-262. https://doi.org/10.4236/ape.2018.82023

Received: April 13, 2018

Accepted: May 26, 2018

Published: May 29, 2018

Copyright $\odot 2018$ by authors and Scientific Research Publishing Inc. This work is licensed under the Creative Commons Attribution-NonCommercial International License (CC BY-NC 4.0). http://creativecommons.org/licenses/by-nc/4.0/

\begin{abstract}
The term hidden curriculum is not new to education or physical education. It is difficult to explain, sometimes hard to identify, but undoubtedly influential to student learning. This paper differentiates the hidden curriculum from an official curriculum. Physical Education Teacher Education (PETE) students (n $=35$ ) in an undergraduate Curriculum Design course were asked to recall their experiences with the hidden curriculum in their formal primary and secondary school physical education experiences, identifying negative and positive outcomes veiled at the time. Eight themes emerged from participant responses and are described with specific examples. Five practices are noted for educators to manage the hidden curriculum.
\end{abstract}

\section{Keywords}

Hidden Curriculum, Physical Education

\section{Introduction}

It is the second lesson of a court invasion games unit in a secondary school. Twenty-five students walk into the gymnasium; some dressed appropriately for physical activity while others are not. Mr. Jay, the physical educator teacher and former semi-professional basketball player, takes attendance. He then announces that students will be divided into three groups and each group will participate in different activities; a basketball game, drills for shooting and passing, and a free-choice game. He picks ten athletic male students for a basketball game and asks the others to select either drill group or free-choice game group. Most female students select to go to the "free-choice" group and begin playing dodgeball. Students in the drill group practice passing and shooting technique as instructed from the teacher. After 15 minutes, Mr. Jay joins in on the basketball game as a player for the rest of class. 
The scene described in the vignette above is not uncommon in many physical education (PE) classes. In particular, in a crowded gymnasium with a large class size, the PE teacher often controls selections and sequences of activities, grouping students, and how much time is allotted for giving feedback on student performances. Being repeatedly exposed to this type of learning environment, students unconsciously learn messages such as the teacher is in control of their learning, athleticism is the most valued trait in PE classes, and boys are favored over girls in physical activities. These student-learning outcomes are gained not from an intended curriculum but from a hidden curriculum. The hidden curriculum refers to lessons that are learned, around such things as the transmissions of norms, values, attitudes, or beliefs that are conveyed in a non-open way in the classroom and by the operation of schooling (Giroux \& Penny, 1983; Martin, 1983; Rink, 2014).

A curriculum is used to describe a set plan, the complete set of experiences, or the learned content of an experience; as a single class session, a set of classes, or a defined period of learning. In any of these formats, it is important to distinguish between planned outcomes and those emerging without prior planning or consideration for future instruction and student learning. The hidden curriculum has had researchers' and practitioners' attention in general and physical education literature over last 40 years. However, the term has not been defined well because it delivers a sense of the complexity of teaching and learning. It conveys messages of grey areas, ambiguous moments, or multidimensional aspects in teaching and learning (Kirk, 2012). The term also has been defined in multiple ways according to different research agendas and interests of different scholars including social skills (Endow, 2012) and discourse and ideology (Kirk, 2012). Due to no-agreed upon definition of hidden curriculum it is often hard for teacher educators to understand how to support teachers to consider the hidden curriculum into their formal, official curriculum (Thomson \& Ennis, 1997).

This paper intends to assist physical educators understand the hidden curriculum with specific examples provided by university students enrolled in a physical education teacher education (PETE) programme in the United States; however, the topic and composition of what the hidden curriculum represents for educators and students is a universal concern and just as relevant in any education settings. The formal curriculum and the hidden curriculum are defined and the importance of understanding the hidden curriculum is examined. PETE students' testimony is recognized with implications and suggestions clearly outlined regarding the hidden curriculum for physical educators and improved teaching practices.

\section{Curriculum and Hidden Curriculum}

Curriculum refers to the learning experiences that occur in a programme (Metzler, 2011); the knowledge, skills, and learning experiences provided to students within a school programme (Lund \& Tannehill, 2010); a long-term plan for what you will teach and what you want students to learn (Rink, 2014). The curriculum 
can be viewed differently by stakeholders (e.g. individual teachers, other school faculty, students, parents, administrators, support staff, etc.). Curriculum is the set of planned experiences with intended outcomes, the expected content to be taught that may include the norms, rituals, and customs established by a school, programme, department, or instructional leader. For educators, it's the sum of experiences of the learner in the programme or school system; to students it could be the learning items necessary for a good grade or passing grade (Siedentop \& Tannehill, 2000).

The curriculum has a clear direction with formative checks to ensure progress. In US school health and physical education programmes, it may be represented as a binder with national and/or state standards, a scope and sequence of instructional units, activities, and skills, and a list of all assessments used to document student learning. In some settings, it is the list of instructional units situated on the school calendar with limited connectivity.

One of the areas of the curriculum that has received a great deal of interest is that of the hidden curriculum. The hidden curriculum includes all experiences occurring (originally unseen) in the holes in a PE programme. It encompasses what is tolerated or unnoticed, perpetuated, and reinforced through intentional and unintentional acts. These rituals of teaching and learning can be both positive and negative. The hidden curriculum includes the demonstrated values of the institution, unplanned and unrecognized values that are taught and learned through the process of education, lessons students that were not the part of the designed learning experience, such as norms, values, or beliefs of teacher or school (Huber, 2003). An exposed hidden curriculum can uncover the social institutions of physical education at the local level and helps inform how pre-service teachers and physical education teacher education (PETE) programmes prepare future professionals for delivering effective instruction. The hidden curriculum can be an issue of power among teacher and students, among PE colleagues. The literature from both physical education and the wider educational community define the hidden curriculum in similar ways, such as the "unintended, implicit experiences that are overlooked" (Lund \& Tannehill, 2010); the culture of the educational climate (Pesut, 2003); experiences comprising what students learn from the school's culture, acceptable and unacceptable behavior (Hilliard, 2000); the overall norms and culture of a student's educational environment (Murray, 2003). A hidden curriculum is one where the dominant discourses in society at large that are embedded in the school curriculum (Thomson \& Ennis, 1997). These experiences are allowed, overlooked, and often beyond the control of the instructional leader. These added experiences are on the periphery but can negatively impact the overall learning environment and cumulative experiences for learners.

\section{The Hidden Curriculum in Physical Education}

The body of research on formal curriculum in physical education continues to grow with the emergence of new and refined instructional models (Metzler, 
McKenzie, van der Mars, Barrett-Williams, \& Ellis, 2013; Metzler, 2011) that compliment Best Practices in teaching skills (Rink, 2010) and aid effective planning for standards-based instruction (Lund \& Kirk, 2010).

Instructional models in physical education (e.g. sport education, cooperative learning, games for understanding, or direct instruction) provide an overall plan, clarify learning priorities, specify an instructional theme, and are backed by research within each model (Metzler, 2011). Rink (2014) outlines effective teaching skills for learning, such as a) designing learning experiences and task, b) content development, and c) developing and maintaining a learning environment among others. Each assumes an overall understanding and grasp of programmatic goals and daily objectives when teaching physical education for student learning.

Instruction informed by national objectives is executed best by beginning at the planning phase, establishing a major unit focus, developing a culminating or summative performance, identifying essential knowledge, skills, and abilities, and designing learning activities (Lund \& Kirk, 2010). Despite the deliberate teachings of the above principles and the broad, comprehensive nature of national standards, primary and secondary physical education programmes leave students bored, uninterested, and alienated (Siedentop \& Tannehill, 2000). Rink (2014) likens an unaligned curriculum to a moving car without a driver. A curriculum is a moving target, dynamic product intended for regular review and revision. When curricular decisions are not used to guide instruction there is no long-term plan.

Nutt and Clarke (2002) addresses the hidden curriculum in detail, including issues of masculinity, femininity, normed behavior of boys and girls, and the importance in attention given to observing behaviors of both teachers and students in the learning environment. For example, one of the critical issues in physical education is related to gender equity (Kirk, 2012). A common behavior in physical education settings observed is teacher's unconscious gender-biased verbal comments (e.g., "throws like a girl", "be the man", "girls can't do this", etc.). The messages conveyed by those teacher comments often encourage gender biases among students, discourage female students' active participation in PE classrooms, and lower self-esteem of male students who are not athletic. This consistently happens because of teachers' lack of awareness of and knowledge about gender bias and the non-explicit stereotypes perpetuating in their classrooms (Duffy, 2013).

\section{Student Perspectives}

Participants $(\mathrm{n}=35)$ of this study were undergraduate Physical Education students in their senior year and one term away from their culminating student teaching experience. Each participant completed separate teaching placements with foci on elementary PE, middle and high school PE, motor development, adapted physical activity, and outdoor education. Using the definition of a hidden curriculum described previously, physical education teacher candidates in 
an undergraduate course in Curriculum Design recalled the negative and positive themes experienced in their K-12 formal PE programmes by completing an exit slip at the end of a class discussion of the hidden curriculum. The exit slip was a blank, half-sheet of paper submitted by each student at the front of the room at the conclusion of class. The authors believed that sharing these examples would increase understanding of this construct and potential impact on student learning, and the timing was appropriate for students to look critically at their own experiences in order to effectively manage hidden outcomes that surface only when the formal curriculum is initiated.

\section{Negative and Positive Outcomes of the Physical Education Hidden Curriculum}

Responses were collected and organized as being negative or positive outcomes with themes emerging for each outcome. Each of the themes is described using specific examples from the student exit slips as well as anecdotes taken by the authors from the course discussion.

\section{Negative}

Low Accountability \& Marginalized Programme. More than two-thirds of all participants identified a lack of accountability as the most troubling aspect in their school physical education programmes. In addition, participants mentioned drifting in a PE class when not held accountable for their own learning; in other words, showing up and passing through the course. If the criteria for a task or a series of tasks in a lesson were made unclear, without teacher differentiation, then students admitted being able to easily fall into the comforts of traditional, ineffective physical education programmes. Over one-half of participants mentioned explicit, ineffective teacher behaviors that led to ineffective student learning. These include spending less time in units due to limited student interest and boredom and not having a planned, coherent curriculum. Teachers were essentially rolling out the ball, a term known in physical education when a teacher offers the space (gym) and equipment (ball) with little or no instruction (Locke, 1992). It may be viewed by students as "free play" or "open gym", or teachers could arrange students in teams to play games in selected sport with limited instructions, rules, and expectations for play during the class or previous lessons. Little accountability gives little or no attention to the common learning domains in physical education (cognitive, affective, \& psychomotor) and student learning is assessed in a "one size fits all" format. One could reasonably expect goals and objectives to be not made clear; a programme unstructured, undecided, unknown, refuted by students, and teacher-driven to a fault in this circumstance (Tinning \& Fitzclarence, 1992).

Over-Emphasis on Competition. An environment vulnerable to unintended, negative student outcomes is one thriving on the highs of winning and lows of losing. Students uninterested in formal competition or the emphasis of competition are marginalized in such a programme (Wright, 2004). More than one-third of the students identified a curriculum reliant on just traditional sports. Partici- 
pants identified traditional team sports, often involving a single ball with large class size. Mostly experienced, skillful students who have direct sports experience outside of PE were the individuals directly involved in the game while others, even in the game, appeared as spectators. In this context a clear winning team and losing team exists, and the impact may feel more high stakes on those marginalized students. In other words, students are praised and honored for winning-students are ignored and casted for losing. The overly competitive environment may be more common than we care to admit. It is a PE programme holding only themed units with skill development, practicing in a scrimmage environment, and applying learned skills in modified or full-sided games (e.g. $11 \mathrm{v} 11$ soccer, 6v6 volleyball). Winning and losing as stark opposites is an outdated norm and opposes maximizing the learning potential of competition (Marshall \& Hardman, 2000).

Biased Curricular Offerings. A limited curriculum favors a limited group of students, types of activities or a specific activity. The curriculum offered in PE classroom could often be based on the preferences of the teacher or a select group of students (e.g., skilled or athletic). Nearly $50 \%$ of the participants listed a curriculum too influenced by teacher interest and not enough by student voice. In this context, teachers could make decisions on what to teach on a daily or lesson-by-lesson basis. Curriculum could be limited and driven by teacher disposition to a fault. Motives may include weather, convenience, tradition, and the all too common notion that "we've always done it this way". Examples of biased curricular decisions by the participants included teachers offering the same instructional units and activities year after year throughout multiple grades and the activities being from the same categories (e.g. team sports, individual sports). Teachers in this format have reduced the list of course offerings based on the limits in their equipment closets rather than the possibilities of their profession.

\section{Positive}

Participants provided positive examples of the PE Hidden Curriculum. Examples were collected with initial analysis and organization into the following themes with examples informed by university PETE students.

Responsibility, Discipline, \& Accountability. Over one-half of participants recalled a clear structure in their PE programmes. Lessons and units and courses had a clear fit and explicit expectations shared regularly in multiple formats. Teachers effectively made expectations clear to students. The PE programme operated in a consistent fashion with very little ambiguity for learning activities and expectations. Students mentioned themes of responsibility, discipline, and accountability as other outcomes based on a positive teacher disposition. Students believed responsibility was best learned when it was modeled, reinforced, and treated as a skill to be taught (Jung \& Wright, 2012). Over one-third of participants listed positive instances of accountability, on much more than behavior; instead, the programme was delivered addressing multiple domains regularly. Accountability was present in skill development, knowledge, and demonstration of such skills. 
Peer Relationships. More than half of participants recalled their K-12 PE experiences where they were offered plenty of opportunities to interact with one another during learning time. One former teacher was described by as a participant as "cognizant" of the setup and "valued positive peer relationships during PE class". The teacher fostered the development of positive interactions and relationships in the class through strong organization, clear direction for teaching and learning, and appropriately sequencing activities and experiences. There was an understanding of the interplay of domains in a physical education setting, and the value each hold in the effective operation (and instruction) that regularly took place. For example, a student in a PE class where cooperative learning was emphasized, recalled the regularity of peer-teaching and students assuming responsibility for most the managerial tasks in each PE lesson. Students would demonstrate an investment in the class and contribute to the goals of the group-goals deliberately established by the teacher. In this environment, students regularly mix with different students, are placed in heterogeneous groups, and are asked to offer perspectives. As described, peer relationships can often be the bi-product of strong teacher-student relationships formed and nurtured by the teacher (Smith, 2003).

\section{Five Practices for Managing the Hidden Curriculum}

As described in participants' negative PE experiences, a hidden curriculum provides room for unplanned and undesired learning outcomes in PE classrooms. However, effectively managing the hidden curriculum allows positive outcomes to emerge. The followings are five strategies for PE teachers to deal with the hidden curriculum to promote students' positive and desirable learning outcomes that are not explicitly included in a formal PE curriculum. The strategies were developed by the participants and the authors, based off lessons learned from participants' practicum experiences, authors' observations and supervisions in K-12 programmes.

Practice \#1: Walk the Talk. The importance of teacher behaviors is regularly underrated and modeling the same behaviors you expect of others provides a visible model for students. Positive and negative feelings toward school and experiences can be tied to the expectations and follow-through of the instructional leader. In short, deliver what you say you will deliver in a programme.

Practice \#2: Know your Bias. Knowing your own biases as an educator may start with completing a self-evaluation, outlining your teaching preferences, tendencies, and detecting any bad instructional or pedagogical habits. Also, welcome opportunities to co-plan with colleagues. Co-planning allows gaps to be filled, brainstorming to take place, and the development of dialogue to form a more critical review of teaching and learning features in a programme. It reduces opportunities for biases to prevail in a PE programme and increases opportunities for internal alignment and innovative practice. Teachers and programmes should strive to plan for internal alignment in a curriculum, assuming the curriculum is always a work in progress. Planning for an internally aligned curricu- 
lum may include: determining the major focus (of an instructional unit), developing summative experiences, identifying essential knowledge, skills, and abilities, designing learning activities, and sharing critical resources (Lund \& Kirk, 2010). Teachers should have a strong sense of their programmes effectiveness, an understanding of their offerings and what is missing in their programme. If a self-evaluation and co-planning with colleagues still leaves a void, ask a colleague to observe your class and identify elements similar to the self-evaluation.

Practice \#3: Conduct a Needs Assessment with your "Clients". Taking the time to gain students' perspectives will be worth it. This does not necessarily mean a summative assessment asking the class at the end of a session how the class went or what they liked/ disliked about a lesson. Instead, it is more about a formative assessment which allows every student to share their perspectives throughout the course and enables instructor to use the information to tailor instruction. By doing so, students can diminish the social anxieties of voicing true opinions aloud to a teacher in front of her/his peers. You may be surprised how useful the information provided by student is when you ask their perspectives of the programme and its offerings, strengths, and areas of improvement. Critical is the genuine interest of the programme in student perspectives and contributions, as well as visible examples of student feedback in the programme within the parameters of meeting the planned programme, state, national standards. Inquiring from students allows programmes and teachers to recognize what is missing and needed in the form of curriculum, equipment, and overall impressions of the educational environment.

Practice \#4: Aim for a Systems-Driven Programme. It is an attempt to articulate all experiences in a programme while understanding the impossibilities of the task, and a call for programmes to be comprehensive systems and low maintenance. To borrow from Rink's (2014) analogy, the car is ready for anyone to drive when given the keys. Required in such a format is regular conversations among stakeholders (faculty) informed by national and state standards, shared responsibilities, and shared understanding of the mission of the programme and purpose of courses, classes, and the curriculum.

Being systems driven allows the programme to take shape, for clients (students) to have a clear sense of the direction of the programme and outline the purposes of the established model. Recommended is clear documentation that articulates what content is offered and how content is taught. These organizational efforts reduce the ambiguity while maintaining a clear direction of the programme. It offers more than just a template for current and future teacher. Emphasizing the importance of the programme, and giving attention and valuing the "programme" enables others (i.e. teachers, students) to build from a pre-existing position.

Practice \#5: Revise, Revise, Revise. This recommendation means a revision of one's instructional delivery and strategies employed with students and considerations for introducing new content or offering content different. The regular practice of revision signifies an attempt to be ahead of or along with the trends 
in the profession, maintain relevance in the field among professionals and students, and be open to change in an ever-changing discipline. Revisions can take place in multiple forms, such as up-to-the-minute changes in learning tasks, daily lessons, assessments, pedagogies, as well as courses and the programme at large. The commitment to revising and critically reviewing one's teaching allows a programme to develop depth.

\section{Conclusion}

The authors believe the curriculum represents what is valued in a physical education programme. There is a hidden curriculum that perpetuates positive or negative outcomes in physical education. Over time, the hidden curriculum becomes quite clear to students. It not only shapes the values, norms, and attitudes of future professionals but also maintains the existing values, norms, and attitudes of working PE professionals. The hidden curriculum is important for physical educators to keep all possible outcomes in mind throughout the planning process, during a lesson, and in post-lesson reflection. As such, PE training programmes should provide opportunities for teachers to identify and reflect on issues associated with all inequities in PE classrooms and further apply such understanding to their instructional practices.

Recommended is a stronger effort for curricular evaluation in-house, a clearer rationale for the decisions physical educators make programmatically and during day-to-day offerings. Addressing and reducing outcomes less desirable involves a thorough analysis of reasons for the emergence of those outcomes, and determines if strong planning can be the greatest influence toward reform. Recommended are attempts to assess the hidden curriculum through student dialogue and promote critical reflection on this topic.

\section{References}

Duffy, D. M. (2013). “Girls Can't Do That": Gender and the "Learning Process" in Physical Education. In L. E. Ciccomascolo, \& E. C. Sulivan (Eds.), The Dimensions of Physical Education (pp. 243-251). Burlington, MA: Jones \& Bartlett Learning.

Endow, J. (2012). Learning the Hidden Curriculum: The Odyssey of One Autistic Adult. Shawnee Mission, KS: AAPC Publishing.

Giroux, H., \& Penna, A. (1983). Social Education in the Classroom; The Dynamics of the Hidden Curriculum. In H. Giroux, \& D. Purpel (Eds.), The Hidden Curriculum and Moral Education (pp. 100-121). Berkeley, CA: McCutchan Publishing Corporation.

Hilliard, J. (2000). The Importance and Limits of Best Evidence Medical Education. Education for Health, 13, 9-13. https://doi.org/10.1080/135762800110529

Huber, S. J. (2003). The White Coat Ceremony: A Contemporary Medical Ritual. Journal of Medical Ethics. 29, 364-366. https://doi.org/10.1136/jme.29.6.364

Jung, J., \& Wright, P. (2012). Application of Hellison's Responsibility Model in South Korea: A Multiple Case Study of 'At-Risk' Middle School Students in Physical Education. Agora for Physical Education and Sport, 14, 140-160.

Kirk, D. (2012). Defining Physical Education: The Social Construction of a School Subject in Postwar Britain. London: Routledge. 
Locke, L. F. (1992). Changing Secondary School Physical Education. Quest, 44, 361-372. https://doi.org/10.1080/00336297.1992.10484062

Lund, J. L., \& Tannehill, D. (2010). Standards-Based Physical Education Curriculum Development (2nd ed.). Sudbury, MA: Jones and Bartlett.

Lund, J., \& Kirk, M. (2010). Performance-Based Assessment for Middle and High School Physical Education (2nd ed.). Champaign, IL: Human Kinetics.

Marshall, J., \& Hardman, K. (2000). The State and Status of Physical Education in Schools in International Context. European Physical Education Review, 6, 203-229.

Martin, J. (1983). What Should We Do with a Hidden Curriculum When We Find One? In H. Giroux, \& D. Purpel (Eds.), The Hidden Curriculum and Moral Education (pp. 122-139). Berkeley, CA: McCutchan Publishing Corporation. https://doi.org/10.1177/1356336X000063001

Metzler, M. (2011). Instructional Models for Physical Education (3rd ed.). Scottsdale, AZ. Holcomb Hathaway.

Metzler, M., McKenzie, T., van der Mars, H., Barrett-Williams, S., \& Ellis, R. (2013). Health Optimizing Physical Education (HOPE): A New Curriculum for School Programmes-Part 1: Establishing the Need and Describing the Model. JOPERD, 84, 41-47. https://doi.org/10.1080/07303084.2013.773826

Murray, J. P. (2003). Realizing New Visions and New Realities: Greetings from the NLN Education Summit.

Nutt, G., \& Clarke, G. (2002). The Hidden Curriculum and the Changing Nature of Teachers' Work. In A. Laker (Ed.), The Sociology of Sport and Physical Education: An Introductory Reader (pp. 148-166). London: Routledge.

Pesut, B. (2003). Developing Spirituality in the Curriculum: Worldviews, Intrapersonal Connectedness, Interpersonal Connectedness. Nursing Education Perspectives, 24, 290-294.

Rink, J. (2014). Teaching Physical Education for Learning (7th ed.). New York, NY: McGraw-Hill.

Siedentop, D., \& Tannehill, D. (2000). Developing Teaching Skills in Physical Education (4th ed.). New York, NY: McGraw-Hill.

Smith, A. L. (2003). Peer Relationships in Physical Activity Contexts: A Road Less Traveled in Youth Sport and Exercise Psychology Research. Psychology of Sport and Exercise, 4, 25-39. https://doi.org/10.1016/S1469-0292(02)00015-8

Thomson, J. R. C., \& Ennis, C. D. (1997). Reproduction and Resistance to the Culture of Femininity and Masculinity in Secondary School Physical Education. Research Quarterly in Exercise and Sport, 68, 89-99. https://doi.org/10.1080/02701367.1997.10608870

Tinning, R., \& Fitzclarence, L. (1992). Postmodern Youth Culture and the Crisis in Australian Secondary School Physical Education. Quest, 44, 287-303. https://doi.org/10.1080/00336297.1992.10484056

Wright, L. J. (2004). Preserving the Value of Happiness in Primary School Physical Education. Physical Education \& Sport Pedagogy, 9, 149-163.

https://doi.org/10.1080/1740898042000294967 